\title{
Acute symptomatic hyponatraemia following sodium picosulfate/magnesium citrate as bowel preparation for colonoscopy-A case series
}

\author{
Hannah Forde*, Triona O'Shea, Colin Davenport, Diarmuid Smith \\ Academic Department of Endocrinology and RCSI Medical School, Beaumont Hospital, Dublin, Ireland; \\ *Corresponding Author: hannahforde@gmail.com \\ Received 6 January 2014; revised 3 February 2014; accepted 17 February 2014 \\ Copyright (c) 2014 Hannah Forde et al. This is an open access article distributed under the Creative Commons Attribution License, \\ which permits unrestricted use, distribution, and reproduction in any medium, provided the original work is properly cited. In accor- \\ dance of the Creative Commons Attribution License all Copyrights (C) 2014 are reserved for SCIRP and the owner of the intellectual \\ property Hannah Forde et al. All Copyright (c) 2014 are guarded by law and by SCIRP as a guardian.
}

\section{ABSTRACT}

Oral purgatives such as sodium phosphate and sodium picosulfate/magnesium citrate (Picolax) combinations are commonly used as a preparation step for colonoscopies in Ireland. These substances can occasionally cause significant electrolyte disturbances including hyponatraemia. Although this is a rare complication of undergoing a colonoscopy, if not treated promptly and appropriately, these electrolyte abnormalities can be associated with life threatening complications. We report cases of symptomatic hyponatraemia in three women aged 65 - 75 years, following ingestion of Picolax in preparation for a colonoscopy. All three patients had documented previously normal electrolytes and all three required hospital admission for management of their electrolyte disturbance. However, the clinical presentations were variable and depended upon the severity of the hyponatraemia. Patient 1 presented with nausea and vomiting 7 hours post Picolax ingestion. Plasma sodium was $124 \mathrm{mmol} / \mathrm{l}$. She was diagnosed with mild symptomatic hyponatraemia, and treated with anti-emetics and slow intravenous infusion of $0.9 \%$ Saline. Patient 2 developed acute confusion 8 hours following ingestion of Picolax. Plasma sodium was $120 \mathrm{mmol} / \mathrm{l}$ and she was clinically dehydrated. She was also treated with intravenous $0.9 \%$ Saline. Patient 3 presented with seizures and reduced GCS, 48 hours post Picolax ingestion. Plasma sodium was $\mathbf{1 1 1}$ $\mathrm{mmol} / \mathrm{l}$. As she had severe life threatening hyponatraemia with seizures, she was treated with boluses of $3 \%$ hypertonic saline. It is recommended that cleansing agents should be used with caution in the elderly, patients with a low seizure threshold, patients with renal impairment, liver cirrhosis, heart failure, and patients on diuretics. These patients should have plasma sodium monitored pre- and post-colonoscopy to ensure early detection of hyponatraemia if present, and to initiate prompt and appropriate management to prevent the serious complications associated with hyponatraemia.

\section{KEYWORDS}

Hyponatraemia; Colonoscopy; Sodium Picosulfate/Magnesium Citrate; Picolax

\section{INTRODUCTION}

Oral sodium picosulfate with magnesium citrate $(\mathrm{Pi}$ colax) is commonly used as a preparation step for colonoscopy. This laxative cleanses the bowel through a dual effect. The sodium picosulfate component of Picolax acts as a stimulant laxative by increasing the force and frequency of the peristalsis in the bowel, while the magnesium citrate component acts as an osmotic laxative by retaining fluids within the colon [1]. It is effective and well tolerated when compared with other bowel cleansers [2]. However, the purgative is associated with electrolyte disturbances including hypocalcaemia, hyperphosphataemia, hypokalaemia, hypomagnesemia, hyper and hyponatraemia. The changes are usually minor and few patients become symptomatic. A prospective study on 144 patients to investigate the effects of sodium picosulfate on serum electrolytes concluded that sodium pico- 
sulfate was associated with reductions in serum sodium concentrations but these reductions were not clinically significant, as sodium levels remained within normal ranges [3].

However, there are reports of severe symptomatic hyponatraemia presenting with seizures in the literature $[4,5]$. Patients with impaired renal handling of water and elderly patients with decreased thirst have an increased risk of developing either hypo- or hypernatraemia following ingestion of purgatives and therefore caution is advised when prescribing them for use in these patients.

We report cases of acute symptomatic hyponatraemia in three women following ingestion of Picolax in preparation for a colonoscopy, and demonstrate the various modes of presentation of this potentially life-threatening condition.

\section{CASE REPORT}

\subsection{Case 1}

A 65-year-old lady self-presented to the Emergency Department with a 4 hour history of nausea and vomiting. Medical history was relevant for hypothyroidism on L-thyroxine with normal thyroid function, stable pulmonary sarcoidosis requiring no treatment and back pain for which she was on Pregabalin. One year previously she had a Hartmanns procedure for management of a perforated diverticulum and was having a colonoscopy prior to reversal of the stoma. Her symptoms began immediately following ingestion of her second dose of Picolax, (7 hours after her first dose) on the day prior to her scheduled colonoscopy. She developed acute nausea followed by hyperemesis. The patient reported vomiting up to 20 times as well as having an increased output from her colostomy. On presentation she was not confused and had a Glasgow Coma Scale (GCS) of 15/15. She was mildly dehydrated with dry mucous membranes but she was not tachycardic. She was normotensive and all other vital signs were within normal limits. Her clinical examination was normal. Her laboratory investigations on admission revealed a plasma sodium of 124 (135 - 145 $\mathrm{mmol} / \mathrm{l})$, potassium of $3.4(3.5-5.3 \mathrm{mmol} / \mathrm{l})$, urea of 4.5 (2.5 - $7.8 \mathrm{mmol} / \mathrm{l})$ and Creatinine of $66(49-90 \mathrm{mmol} / \mathrm{l})$ Patient had normal electrolytes recorded 7 months previously. Spot urinary sodium on day of admission was 63 $\mathrm{mmol} / \mathrm{l}$ and urine osmolality was $316 \mathrm{mosm} / \mathrm{kg}$. She was diagnosed with Picolax induced hyponatraemia and was treated with anti-emetics and slow intravenous fluid. She received 2 litres of normal Saline over 24 hours aiming for a correction in plasma sodium of no more than 12 mmol over the 24 hour period. She was discharged home well after 36 hours and her plasma sodium at time of discharge was $139 \mathrm{mmol} / \mathrm{l}$.

\subsection{Case 2}

A 74-year-old female was referred to the Emergency department by her General Practitioner (GP) with an acute confusional state. Past history was relevant for limited scleroderma and hypertension treated with Candesartan and Atenolol only. 1 day prior to presentation she had started the bowel cleansing preparation Picolax for an elective colonoscopy to investigate faecal incontinence. 8 hours after starting Picolax she became acutely confused. On arrival she was extremely agitated, and incoherent with a GCS of 13 out of 15 . Clinical examination was difficult as she refused to cooperate or give a urine sample and was unable to stand. She did have signs of clinical dehydration including dry mucous membranes, decreased skin turgor and sinus tachycardia. Plasma sodium on admission was 120 (135 - $145 \mathrm{mmol} / \mathrm{l})$, blood urea of 8.3 (2.5 - $8.5 \mathrm{mmol} / \mathrm{l})$ and creatinine of 97 (49 $90 \mu \mathrm{mol} / \mathrm{l})$. Previous urea and electrolytes had been normal.

A diagnosis of symptomatic hypovolemic hyponatraemia was made. She was started on gentle fluid resuscitation with $0.9 \%$ isotonic saline with 2 hourly urea and electrolyte levels to ensure an appropriate rise in plasma sodium (Table 1). Her plasma sodium corrected slowly over the next 12 - 24 hours and her cognition returned to normal. Thyroid function, short synacthen test and Computerised Tomography (CT) of the brain were normal. 48 hours after admission she was discharged well and on follow up her plasma sodium remains normal.

\subsection{Case 3}

A 73-year-old lady was brought to hospital via ambulance following a tonic clonic seizure. This patient underwent a pelvic ultrasound scan earlier that day for investigation of an ovarian cyst and 1 day prior to the ultrasound she had a colonoscopy with Picolax as the bowel preparation.

Table 1. Trend of electrolyte measurements during the admission.

\begin{tabular}{ccccc}
\hline & Time & Urea & Sodium (Na) & Potassium (K) \\
\hline Day 1 & $08: 00$ & 8.3 & 120 & 4.1 \\
& $11: 00$ & 7.8 & 123 & 4.4 \\
& $13: 00$ & 7.4 & 127 & 4.2 \\
& $15: 00$ & 7.1 & 126 & 4.3 \\
& $17: 00$ & 6.8 & 127 & 4.3 \\
& $19: 00$ & 6.5 & 130 & 4.3 \\
& $23: 00$ & 6.1 & 132 & 4.0 \\
Day 2 & $09: 00$ & 6.8 & 133 & 3.6 \\
\hline
\end{tabular}


Her past medical history was significant for hypothyroidism with normal thyroid function on L-thyroxine.

During her Pelvic Ultrasound, the patient complained of feeling nauseated and subsequently vomited multiple times. 3 hours later, while at home, she collapsed and had a witnessed tonic clonic seizure. On presentation to the Emergency Department, she was post ictal, with a GCS of 11/15. Her neurology exam was grossly normal apart from up going left sided plantars. She had an urgent CT scan of the brain which was normal. The initial impression offered by the admitting medical staff was that she had suffered an acute brain stem infarction. An intravenous Phenytoin infusion was commenced for management of her seizures. Initial laboratory investigations revealed hyponatraemia with a plasma sodium of $115 \mathrm{mmol} / \mathrm{l} .6$ hours later, she had a second seizure and GCS dropped to 6/15 post ictally and the endocrine service were then asked to be involved in her care. On examination, she was hypertonic in all 4 limbs, plantars were up going, gaze was deviated to the right and pupils were dilated and sluggish. She was intubated and ventilated and transferred to the intensive care unit (ICU). Repeat plasma sodium was $111 \mathrm{mmol} / \mathrm{l}$. She was clinically euvolaemic and passing $100 \mathrm{mls}$ urine per hour. Urinary sodium was elevated at $142 \mathrm{mmol} / \mathrm{l}$ with a urine osmolality was $656 \mathrm{mosm} / \mathrm{kg}$. She was treated for acute severe symptomatic hyponatraemia with a bolus infusion of $100 \mathrm{mls}$ of $3 \%$ hypertonic saline, aiming for a target rise in the plasma sodium of between 0.5 to $1 \mathrm{mmol}$ rise per hour in the plasma sodium per bolus infusion. She required three bolus infusions in total of $3 \%$ hypertonic saline to gradually increase her plasma sodium to 120 $\mathrm{mmol} / \mathrm{l}$ (Table 2). The hypertonic saline was then stopped and she was placed on a fluid restriction of 800 $\mathrm{mls} / 24$ hours.

Over the next four hours, the patient had a large diuresis passing up to $800 \mathrm{mls} /$ hour and her plasma sodium rose to $127 \mathrm{mmol} / \mathrm{l}$. She was treated with a bolus infusion of $300 \mathrm{mls}$ of 5\% Dextrose and Desmopressin $1 \mathrm{mcg}$ intravenously to stop the rise in plasma sodium. Her urine volumes returned to appropriate levels and her plasma sodium stabilized. She was subsequently extubated and repeat neurological exam was normal. Magnetic Resonance Imaging (MRI) of her brain was normal with no signs of Central Pontine Myelinosis (CPM). Over the next 24 hours, the patient remained on a fluid restriction of $1000 \mathrm{mls} /$ day. The plasma sodium normalised and stayed within normal limits for the remainder of her admission.

Synacthen test showed normal cortisol response with a peak cortisol $>900 \mathrm{nmol} / \mathrm{l}$. CT scan of the thorax, abdomen and pelvis demonstrated intrahepatic and pancreatic duct dilatation. Magnetic Resonance Cholangiopancreatography (MRCP) was normal with no evidence of a ma-
Table 2. Trend of electrolyte measurements during the first four days of admission.

\begin{tabular}{|c|c|c|c|c|c|}
\hline & Time & Urea & Sodium & Potassium & Actions Taken \\
\hline \multirow[t]{2}{*}{ Day 1} & $15: 00$ & 3.4 & 115 & 3.7 & \\
\hline & 23:00 & 3.4 & 111 & 3.7 & \\
\hline \multirow[t]{8}{*}{ Day 2} & 01:00 & 3.0 & 111 & 3.4 & $\begin{array}{c}100 \mathrm{mls} \\
\text { hypertonic saline }\end{array}$ \\
\hline & 03:00 & 3.0 & 112 & 3.7 & \\
\hline & 04:30 & 3.0 & 116 & 3.7 & \\
\hline & 08:00 & 3.0 & 113 & 3.7 & \\
\hline & $11: 00$ & 3.3 & 114 & 3.4 & $\begin{array}{c}100 \mathrm{mls} \text { of } \\
\text { hypertonic saline }\end{array}$ \\
\hline & $13: 00$ & 3.1 & 118 & 3.3 & $\begin{array}{c}50 \mathrm{mls} \text { of } \\
\text { hypertonic saline }\end{array}$ \\
\hline & $16: 00$ & 3.2 & 120 & 4.2 & \\
\hline & $20: 00$ & 2.9 & 127 & 3.7 & $300 \mathrm{mls} 5 \%$ Dextrose \\
\hline \multirow[t]{5}{*}{ Day 3} & 03:00 & 3.2 & 128 & 3.9 & $1 \mathrm{mcg}$ Desmopressin \\
\hline & 09:00 & 3.4 & 129 & 3.7 & \\
\hline & $13: 00$ & 4.8 & 127 & 3.9 & \\
\hline & $18: 00$ & 4.6 & 130 & 3.6 & \\
\hline & $23: 00$ & 4.0 & 130 & 3.6 & \\
\hline \multirow[t]{2}{*}{ Day 4} & 02:00 & 3.3 & 133 & 3.8 & \\
\hline & 07:00 & 4.0 & 135 & 3.6 & \\
\hline
\end{tabular}

lignancy. She made a full recovery and on follow up remains well with a normal plasma sodium.

\section{DISCUSSION}

All of the cases presented with acute symptomatic hyponatraemia following the ingestion of Picolax in preparation for a routine out-patient colonoscopy.

Hyponatraemia is not uncommon following colonoscopy and can occur in up to $7.5 \%$ of patients [6]. Sodium picosulfate does not by itself affect the plasma sodium concentration. The cleansing agent can lead to diarrhoea, dehydration and a fall in the plasma volume which stimulates baroregulated secretion of vasopressin, which increases the thirst response causing excessive fluid intake and hyponatraemia. Similarly, nausea and vomiting are both strong stimulators of vasopressin secretion which lead to further water retention and a subsequent fall in the plasma sodium.

In our case series, the hyponatraemia developed acutely following ingestion of Picolax in patients who previously had normal electrolytes, and the presentations of hyponatraemia ranged from mild to very severe.

Patient 1 and patient 2 had moderate hyponatraemia 
with plasma sodium levels between 120 - $130 \mathrm{mmol} / \mathrm{l}$. Their symptoms however, varied from nausea and vomiting only, to confusion, agitation and poor balance. Patient 1 had a urinary sodium of $63 \mathrm{mmol} / \mathrm{l}$ suggesting that her hyponatraemia was not due to hypovolemia from vomiting alone but also increased vasopressin secretion coupled with a resultant increase in thirst response triggered by her nausea and vomiting secondary to Picolax ingestion. These two patients were treated with gentle fluid resuscitation with isotonic $(0.9 \%)$ normal saline as they were clinically hypovolaemic. They both had an improvement in their clinical and biochemical status over 24 hours and were discharged home after 2 days.

Patient 3 had severe hyponatraemia and required ICU admission. She met the criteria for treatment with 3\% hypertonic saline as she was seizing. Close monitoring of plasma sodium every 2 hours is required when patients receive hypertonic saline as too rapid a correction of the plasma sodium can lead to cerebral demyelination and CPM [7]. Development of CPM was a concern in this patient, given the rapid increase in plasma sodium following her large diuresis. Fortunately, she responded well to 5\% Dextrose bolus infusion and Desmopressin and plasma sodium levels stablilised.

There are isolated case reports in the literature of severe hyponatraemia following Picolax ingestion in preparation for a colonoscopy $[4,5,8]$. These patients presented with seizures and had serum sodium levels ranging from $110 \mathrm{mmol} / \mathrm{l}-120 \mathrm{mmol} / \mathrm{l}$. One patient subsequently developed rhabdomyolysis, which may have been a complication of the hyponatraemia or associated with the seizure activity [8]. These cases had favourable outcomes and the patients recovered completely with no neurological sequelae, as prompt appropriate management was initiated to correct the life threatening hyponatraemia. Severe hyponatraemia has also been reported with the use of bowel cleansers containing Sodium Phosphate and Polyethelene Glycol [4,9].

The reason why a small number of patients on cleansing agents develop significant hyponatraemia may result from differences in oral fluid intake amongst patients. Both increased free water intake coupled with increased vasopressin secretion appear to be necessary for the development of acute severe hyponatremia [9]. Patient 3 was scheduled for a pelvic ultrasound scan 1 day after her colonoscopy, and had been instructed to drink large volumes of fluids to maintain a full bladder, thereby exacerbating her electrolyte imbalance and causing a more severe hyponatraemia than the other two cases.

\section{CONCLUSION}

In conclusion, acute symptomatic hyponatraemia secondary to Picolax is a rare but recognized complication of screening colonoscopy. It is recommended that cleansing agents should be used with caution in the elderly, patients with a low seizure threshold, patients with impaired ability to excrete free water including those with renal impairment, liver cirrhosis or heart failure, as well as those on diuretics in particular thiazide diuretics. Such individuals require increased surveillance, including measurement of plasma sodium pre- and post-colonoscopy or admission to hospital during the bowel preparation for intravenous hydration. If acute symptomatic hyponatraemia occurs, prompt treatment is required to prevent the development of cerebral oedema.

\section{REFERENCES}

[1] Jauch, R., Hankwitz, R., Beschke, K. and Pelzer, H. (1975) Bis-(p-hydroxyphenyl)-pyridyl-2-methane: The common laxative principle of bisacodyl and sodium picosulfate. Arzneimittel-Forschung, 25, 1796.

[2] Regev, A., Fraser, G. and Delpre, G. (1998) Comparison of two bowel preparations for colonoscopy: Sodium picosulphate and magnesium citrate versus sulphate free polyethylene glycol lavage solution. American Journal of Gastroenterology, 93, 1478-1482.

http://dx.doi.org/10.1111/j.1572-0241.1998.00467.x

[3] Ryan, F., Anobile, T., Scutt, D., Hopwood, M. and Murphy, G. (2005) Effects of oral sodium picosulphate Picolax on urea and electrolytes. Nursing Standard (Royal College of Nursing (Great Britain)), 19, 41.

[4] Frizelle, F.A. and Colls, B.M. (2005) Hyponatremia and seizures after bowel preparation: Report of three cases. Diseases of the Colon and Rectum, 48, 393-396. http://dx.doi.org/10.1007/s10350-004-0778-6

[5] Dillon, C.E. and Laher, M.S. (2009) The rapid development of hyponatraemia and seizures in an elderly patient following sodium picosulfate/magnesium citrate (Picolax). Age and Ageing, 38, 487-487.

http://dx.doi.org/10.1093/ageing/afp054

[6] Cohen, C.D., Keuneke, C., Schiemann, U., Schroppel, B., Siegert, S., Rascher, W., et al. (2001) Hyponatraemia as a complication of colonoscopy. The Lancet, 357, 282-283. http://dx.doi.org/10.1016/S0140-6736(00)03619-9

[7] Smith, D.M., McKenna, K. and Thompson, C.J. (2000) Hyponatraemia. Clinical Endocrinology (Oxf), 52, 667678. http://dx.doi.org/10.1046/j.1365-2265.2000.01027.x

[8] Dig, R.E.E. (2013) Severe rhabdomyolysis and hyponatremia induced by picosulfate and bisacodyl during the preparation of colonoscopy. Revista Española de Enfermedades Digestivas, 105, 180-182. http://dx.doi.org/10.4321/S1130-01082013000300016

[9] Chen, H., Chen, C., Chu, P., Chao, P. and Lin, S. (2006) Acute hyponatremic encephalopathy after preparation for colonoscopy. Journal of Medical Sciences-Taipei, 26, 33. 